\title{
Independencia y legitimidad de la jurisdicción constitucional: en perspectiva Colombia - Bolivia*
}

\author{
Independence and legitimacy of the constitutional \\ jurisdiction: in perspective Colombia - Bolivia
}

Jaime Cubides Cárdenas**

Sebastián Rangel Salazar***

Laura Milena Beltrán Galvis****

Artículo de investigación

Fecha de Recepción: 13 de enero de 2021

Fecha de Aceptación: 28 de febrero de 2021

\section{Para citar este artículo:}

Cubides Cárdenas, J., Rangel Salazar, S. y Beltrán Galvis, L. M. (2021). Independencia y legitimidad de la jurisdicción constitucional: en perspectiva Colombia - Bolivia. Revista Análisis Jurídico-Político, 3(5), 95-110. https://doi.org/10.22490/26655489.4586

\footnotetext{
* Artículo que expone resultados de investigación del proyecto titulado Desafíos Contemporáneos para la protección de derechos humanos en escenarios de emergencia y construcción de paz - Fase III, que forma parte de la línea de investigación Fundamentación e implementación de los Derechos Humanos, del grupo de investigación Persona, Instituciones y Exigencias de Justicia, reconocido y categorizado como Tipo A1 por Minciencias y registrado con el código COL0120899, vinculado al Centro de Investigaciones Socio jurídicas (cIsJuc), adscrito y financiado por la Facultad de Derecho de la Universidad Católica de Colombia.

** Abogado y especialista en Derecho Público por la Universidad Autónoma de Colombia. Especialista y magíster en Docencia e Investigación con énfasis en las Ciencias Jurídicas por la Universidad Sergio Arboleda y magíster en Derecho de la misma casa de estudios. Estudiante de Doctorado en Derecho de la Universidad Católica de Colombia. Docente asociado, investigador senior y líder del grupo de investigación Persona, Instituciones y Exigencias de Justicia, con código COL0120899, con categoría A1 en Minciencias, y el cual está vinculado al Centro de Investigaciones Socio-Jurídicas de la Universidad Católica de Colombia (cIsJuc). Contacto: jacubides@ucatolica.edu.co oRcID: https://orcid.org/00000002-6542-6892
} 


\section{Resumen}

Este artículo reflexiona sobre el control judicial a partir de la revisión de fuentes doctrinales y jurídicas que permitan mostrar la característica política de los tribunales constitucionales, para así explicar las teorías sobre la elección de los magistrados haciendo una corta comparación con algunos países latinoamericanos; por último, se explica de forma detallada el caso boliviano. Lo anterior lleva al siguiente interrogante: ¿la forma de elección de los magistrados implementada en Bolivia perjudica la legitimidad e independencia de los tribunales constitucionales, si se toma como ejemplo el caso colombiano? Para dar respuesta a esta pregunta se desarrollan cuatro apartados: 1) independencia y legitimidad del juez y el tribunal constitucional; 2) formas de elección de los magistrados; 3) el carácter político del Tribunal Constitucional; 4) interrogantes al Tribunal Constitucional Plurinacional de Bolivia. Para finalizar, se darán unas breves conclusiones que buscan dar respuesta a este conflicto entre legitimidad e imparcialidad.

Palabras clave: constitucionalidad, imparcialidad, jurisdicción, legitimidad, tribunal.

\section{Abstract}

This text will reflect on judicial control from the review of doctrinal and legal sources that allow showing the political characteristic of

\footnotetext{
*** Estudiante de Derecho de la Universidad Católica de Colombia. Integrante del semillero de investigación Observatorio de Justicia Constitucional y Derechos Humanos, perteneciente al grupo de investigación Persona, Instituciones y Exigencias de Justicia, con código COL0120899, con categoría A1 de Minciencias, que está vinculado al Centro de Investigaciones SocioJurídicas de la Universidad Católica de Colombia (cIsJuc). Contacto: srangel67@ucatolica.edu.co ORCID: https://orcid.org/0000-0002-6196-7886

**** Egresada de la facultad de Derecho de la Universidad Católica de Colombia. Auxiliar de investigación del grupo de investigación Persona, Instituciones y Exigencias de Justicia, e integrante del semillero de investigación Observatorio de Justicia Constitucional de Derechos Humanos vinculado al Centro de Investigaciones Socio-Jurídicas (cISJuc), adscrito y financiado por la facultad de Derecho de la Universidad Católica de Colombia. Contacto: Imbeltran42@ucatolica.edu.co oRcID: https://orcid.org/0000-0003-4347-5551
} 
Jaime Cubides Cárdenas - Sebastián Rangel Salazar - Laura Milena Beltrán Galvis Independencia y legitimidad de la jurisdicción constitucional: en perspectiva Colombia - Bolivia

constitutional courts, in order to explain the theories on the election of magistrates by making a short comparison with some Latin American countries. And finally, we will explain the Bolivian case in detail. The foregoing leads to the following question: Does the form of election of magistrates implemented in Bolivia harm the legitimacy and independence of the constitutional courts, taking the Colombian case as an example? To answer this question, four sections are developed: 1 . Independence and legitimacy of the judge and the constitutional court; 2 . Forms of election of magistrates; 3. The political character of the constitutional court; 4. Questions to the Plurinational Constitutional Court of Bolivia; and finally we will end by giving some brief conclusions seeking to respond to this conflict between legitimacy and impartiality.

Keywords: Constitutionality; Court; Impartiality; Jurisdiction; Legitimacy.

\section{INTRODUCCIÓN}

En países como Colombia, Bolivia, Venezuela, Ecuador y Chile se han desarrollado teorías como el neoconstitucionalismo o el nuevo constitucionalismo latinoamericano en busca del fortalecimiento de la democracia, la ampliación de derechos sociales y la defensa de la supremacía de la constitución, lo que ha significado pasos de gigante respecto a la parte dogmática de la constitución, aunque con pocos avances igualitarios respecto a la parte orgánica, que corresponde a la organización del poder que aún mantiene un matiz contramayoritario (Gargarella, 2019).

Así mismo, se ha visto cómo en la última década del siglo XX y la primera del siglo XXI, debido a la influencia de estos movimientos, en América Latina se han desarrollado una serie de reformas constitucionales que han dado como resultado el paso de una jurisdicción constitucional en manos de la jurisdicción ordinaria a la creación de tribunales constitucionales en estricto sentido (Nogueira, 2003). Esto ha hecho que el papel de la jurisdicción constitucional sea más relevante en lo que respecta a la guarda e interpretación de la carta 
magna mediante el uso de instrumentos como la inexequibilidad de las leyes con el fin de cumplir su tarea. Labores como esta han llevado a que varios académicos se cuestionen acerca del papel democrático de los jueces, principalmente por tres razones: 1) no son elegidos democráticamente; 2) pueden objetar leyes que a su parecer sean inconstitucionales; y 3) la jurisdicción constitucional puede declarar la inconstitucionalidad de leyes dictadas por el legislativo, que es un órgano representativo y goza de una legitimidad directa; esto ha dado origen a la recepción de la dificultad contramayoritaria en América Latina (Rivera, 2010).

El siguiente artículo presenta una revisión del particular caso de Bolivia, donde el control judicial ha ganado campo y se ha pretendido brindar legitimidad al Tribunal Constitucional. A partir de la entrada en vigor de su nueva constitución, los magistrados de las altas cortes del país son designados mediante elección popular. Hasta aquí pareciera que, en el caso boliviano, la cuestión democrática del juez termina; sin embargo, esta forma de elección no da garantías de imparcialidad, como explicaremos más adelante.

\section{INDEPENDENCIA Y LEGITIMIDAD DEL JUEZ Y EL TRIBUNAL Constitucional}

La potestad inherente a los tribunales constitucionales de realizar un control judicial sobre las leyes (Vanegas, 2014) ha producido un debate entre quienes consideran que, por un lado, este control judicial es antidemocrático y quienes defienden, por otro lado, esta facultad de los jueces (Agudelo, 2014).

$\mathrm{Al}$ respecto, es menester traer a colación el concepto de dificultad contramayoritaria, elaborado por el jurista rumano Alexander Bickel en su obra The Least Dangerous Branch - The Supreme Court at the Bar of Politics (1962). En este libro, Bickel hace un desarrollo de esta noción, brindando respuesta a la tensión entre democracia y 
Jaime Cubides Cárdenas - Sebastián Rangel Salazar - Laura Milena Beltrán Galvis Independencia y legitimidad de la jurisdicción constitucional: en perspectiva Colombia - Bolivia

control judicial y a la propuesta de limitar el poder judicial ${ }^{1}$. Que un tribunal compuesto por miembros no elegidos por el pueblo declare nula una norma o decisión de un órgano elegido democráticamente como el legislativo o el ejecutivo (Tushnet, 2012, citado en Agudelo, 2014, p. 74) es la razón principal por la cual se dice que los jueces ejercen un poder contramayoritario. Este argumento es, sobre todo, una crítica a la carencia de democracia del poder judicial (Verly, 1991).

Quienes defienden esta potestad del juez constitucional tienen en común el defender una perspectiva de democracia más amplia², en la que el Tribunal cumple la tarea primordial de protección de derechos constitucionales; tales son los casos de Luigi Ferrajoli, Carlos Santiago Nino y John Ely (Vázquez, 2010). Ferrajoli (1999) considera que la tarea de la jurisdicción constitucional está encaminada a proteger los derechos fundamentales que la constitución establece, dado que la carta política dicta derechos que no son fruto del conceso de la mayoría, sino que radican su legitimidad en la igualdad de todos respecto de las libertades y derechos sociales, que son precisamente límites a las actuaciones del gobierno o el congreso.

Por su parte, Nino, en el ensayo La Filosofía del Control Judicial de Constitucionalidad, realiza la siguiente pregunta: “ipor qué estos órganos contramayoritarios (jueces y cortes) van a prevalecer sobre los órganos representativos de la soberanía popular en una serie de cuestiones que tienen que ver con los derechos de los individuos?" (Nino, 1989, p. 84), a la que responde dando su visión de democracia, que consiste en una discusión mayoritaria de los intereses de gran parte de la población, para llegar así a soluciones fundamentales caracterizadas por tener un margen amplio de imparcialidad debido a lo amplio del procedimiento democrático.

1 Cabe aclarar que la dificultad contramayoritaria ha tenido una interpretación incorrecta como un problema contramayoritario, que permite a los llamados "escépticos del control judicial" proponer límites al poder judicial (Agudelo, 2014, p. 36).

2 Diferente por ejemplo a Rousseau, para quien la rama judicial debería cumplir un papel principalmente técnico. 
Esta idea de democracia es la que da pie a que se limite a los órganos mayoritarios, pues "Lo único que la mayoría no tiene legitimidad para decidir es la restricción de las condiciones y los presupuestos que hacen del procedimiento democrático un mecanismo apto para encontrar soluciones correctas." (Nino, 1989, p. 87). En consecuencia, se justifica el papel activista de los jueces como protectores y garantes del proceso democrático. Por ejemplo, en el caso Yean y Bosico vs. República Dominicana, en el que el Estado negaba a estas niñas los derechos a la nacionalidad, a ser reconocidas por la ley y subsidiariamente el derecho a la educación y al voto, aquí la Corte Interamericana de Derechos Humanos, al reconocerle estos derechos a las menores, falló poniéndolas en igualdad de condiciones para que puedan participar del debate amplio del proceso democrático.

Igualmente, John Ely ${ }^{3}$ busca vindicar el control judicial de constitucionalidad a partir de argumentos que tienen en común la protección de los jueces al proceso democrático (Verly, 1991). Al igual que Nino, Ely considera que los jueces están llamados a garantizar el procedimiento epistémico democrático, asegurando la participación de las minorías.

\section{Formas de elección de los miembros del Tribunal}

Ahora bien, teniendo en cuenta las anteriores razones en defensa del control judicial de la constitucionalidad, se puede sostener que los jueces desempeñan un rol fundamental en una sociedad democrática. Sin embargo, a pesar de las fundamentaciones que llevan a ello, "La pregunta, entonces, es cómo garantizar la independencia judicial si los jueces son designados, finalmente, por el poder político" (Vázquez, 2010). Es decir, resuelta la dificultad contramayoritaria, nos permitimos preguntar: ¿qué implicación

3 De acuerdo con Agudelo (2014), la idea de que los jueces en democracias deliberativas protegen los mecanismos de participación es recibida en América Latina gracias a la traducción que se hace de John Ely, en 1980, y en Colombia, en 1997 (Agudelo, 2014, p. 75-76). 
Jaime Cubides Cárdenas - Sebastián Rangel Salazar - Laura Milena Beltrán Galvis Independencia y legitimidad de la jurisdicción constitucional: en perspectiva Colombia - Bolivia

puede tener la forma de elección de los magistrados en su forma de decidir?

Maurice Duverger (1980), en su libro Instituciones Políticas y Derecho Constitucional, habla de los medios de independencia de las jurisdicciones. De acuerdo con la forma de reclutamiento o elección de los jueces, enuncia los siguientes sistemas: por voto universal, los jurados y por carrera. La elección de los jueces por voto universal es muy común en algunos estados de Estados Unidos y permite brindar más legitimidad a estos. Incluso los ciudadanos pueden revocarlos por medio de un sistema llamado "recall". Sin embargo, este sistema no ha dado buenos resultados, pues para afrontarse a las elecciones de los candidatos que deberán ocupar las funciones jurisdiccionales, estos se han aliado a los partidos políticos, lo que evita una independencia judicial y una función imparcial (Duverger, 1980).

Sobre los jurados menciona que, al ser ciudadanos elegidos por medio de sorteo y ejercer funciones jurisdiccionales temporalmente, su independencia reside en la forma de ser elegidos: el sorteo. Finalmente, sobre la elección de magistrados por medio de carrera podemos decir que es la más idónea. En este caso, su independencia se garantiza por medios técnicos; Duverger enumera tres, los cuales son:

1. Garantías de reclutamiento: es posible garantizar la independencia de los magistrados frente a los gobernantes. Por ejemplo, en Francia, el sistema de elección inicia con un concurso y solo pueden ser elegidos de acuerdo con la clasificación de las listas.

2. Garantías de inamovilidad: este medio refiere a la imposibilidad de revocar, promover o desplazar de sus funciones a los magistrados, salvo cometan una falta que constituya una inhabilidad o incompatibilidad.

3. Garantías de ascenso: pasado cierto tiempo en el cargo, el magistrado puede ser ascendido (sin embargo, esto no aplica a los tribunales constitucionales latinoamericanos, debido a que son órganos de cierre y no tienen superiores). 


\subsection{Criterios formales e informales en la elección de los MAGISTRADOS}

Repasadas las formas en las que es posible elegir a los miembros de un Tribunal Constitucional, es necesario tener presente que en un proceso de elección pueden influir otros criterios de carácter formal, es decir, establecidos en normas, así como también criterios informales que no se encuentran en la ley, pero que son decisivos en la elección de estos funcionarios.

En varios países, para llegar a ocupar el cargo de magistrado existen algunos requisitos formales consistentes en un régimen de inhabilidades e incompatibilidades, una edad mínima, cierto tiempo de ejercer la profesión, un buen prestigio, entre otros, que buscan que los jueces ejerzan su cargo de forma idónea e imparcial (Fernández, 1993). Respecto de este régimen, cabe resaltar la prohibición existente en algunos países latinoamericanos de que los miembros de las altas cortes participen o pertenezcan a actividades o movimientos de política partidista, como se muestra en la tabla 1.

Tabla 1. Elección de magistrados

\begin{tabular}{|c|c|c|}
\hline País & Forma de elección & Prohibición \\
\hline Bolivia & $\begin{array}{l}\text { Elección popular (artículo } 198 \\
\text { de la Constitución del Estado } \\
\text { Plurinacional de Bolivia). }\end{array}$ & $\begin{array}{l}\text { Ley del estatuto del funcionario } \\
\text { público, } 22 \text { de octubre de } 1999 . \\
\text { Artículo } 9 . \text { literal b: realizar activida- } \\
\text { des políticas partidarias y de interés } \\
\text { particular durante la jornada laboral } \\
\text { o en el ejercicio de sus funciones. }\end{array}$ \\
\hline Colombia & $\begin{array}{l}\text { Elegidos por el Senado de } \\
\text { la República para periodos } \\
\text { individuales de } 8 \text { años, de } \\
\text { sendas ternas presentadas por } \\
\text { el presidente de la República, } \\
\text { la Corte Suprema de Justicia y } \\
\text { el Consejo de Estado (artículo } \\
239 \text { de la Constitución Política } \\
\text { de Colombia). }\end{array}$ & $\begin{array}{l}\text { A los empleados del Estado que se } \\
\text { desempeñen en la rama judicial, en } \\
\text { los órganos electorales, de control } \\
\text { y de seguridad, les está prohibido } \\
\text { tomar parte en las actividades de } \\
\text { los partidos y movimientos y en las } \\
\text { controversias políticas, sin perjuicio } \\
\text { de ejercer libremente el derecho al } \\
\text { sufragio. A los miembros de la fuerza } \\
\text { pública en servicio activo se les apli- } \\
\text { can las limitaciones contempladas } \\
\text { en el artículo } 219 \text { de la Constitución } \\
\text { (artículo } 127 \text { de la Constitución } \\
\text { Política de Colombia, inciso 2). }\end{array}$ \\
\hline
\end{tabular}


Jaime Cubides Cárdenas - Sebastián Rangel Salazar - Laura Milena Beltrán Galvis Independencia y legitimidad de la jurisdicción constitucional: en perspectiva Colombia - Bolivia

Tabla 1. Elección de magistrados (continuación)

\begin{tabular}{|c|c|c|}
\hline País & Forma de elección & Prohibición \\
\hline Ecuador & $\begin{array}{l}\text { Los miembros de la Corte } \\
\text { Constitucional se designarán } \\
\text { por una comisión calificadora } \\
\text { que estará integrada por dos } \\
\text { personas nombradas por cada } \\
\text { una de las funciones, legislati- } \\
\text { va, ejecutiva y de transparencia } \\
\text { y control social. La selección de } \\
\text { los miembros se realizará de } \\
\text { entre las candidaturas presen- } \\
\text { tadas por las funciones anterio- } \\
\text { res, a través de un proceso de } \\
\text { concurso público, con veeduría } \\
\text { y posibilidad de impugnación } \\
\text { ciudadana. En la integración } \\
\text { de la Corte se procurará la pa- } \\
\text { ridad entre hombres y mujeres } \\
\text { (artículo } 434 \text { de la Constitución } \\
\text { del Estado del Ecuador). }\end{array}$ & $\begin{array}{l}\text { No pertenecer ni haber pertenecido } \\
\text { en los últimos diez años a la directi- } \\
\text { va de ningún partido o movimiento } \\
\text { político (numeral } 5 \text {, artículo } 433 \text { de } \\
\text { la Constitución Política del Estado } \\
\text { del Ecuador). }\end{array}$ \\
\hline Perú & $\begin{array}{l}\text { Son designados por el Congreso } \\
\text { mediante resolución legislativa, } \\
\text { con el voto de los dos tercios del } \\
\text { número legal de sus miembros } \\
\text { por medio de comisiones de } \\
\text { siete o nueve congresistas } \\
\text { (artículo } 201 \text { de la Constitución } \\
\text { Política del Perú). }\end{array}$ & $\begin{array}{l}\text { Está prohibido a los jueces: parti- } \\
\text { cipar en política, sindicalizarse y } \\
\text { declararse en huelga (artículo } 40 \text {, } \\
\text { numeral 5, ley de Carrera Judicial } \\
\text { no 29277). }\end{array}$ \\
\hline
\end{tabular}

Fuente: elaboración propia ${ }^{4}$.

En contravía con este tipo de prohibición, podemos mencionar el caso del consejo constitucional francés. De acuerdo con la normatividad de este país, los miembros de este tribunal no tienen la prohibición de participar en actividades de política partidista, incluso pueden postularse a las elecciones (Fernández, 1993). Considerados los que se pueden llamar criterios formales, se aborda

4 Basado en la Constitución Política del Perú, Constitución Política del Ecuador, Constitución Política de Colombia, Constitución del Estado Plurinacional de Bolivia, ley de Carrera Judicial del Perú 29277, ley del Estatuto del Funcionario Público, del 22 de octubre de 1999 en Bolivia. 
lo que Ana María Montoya (2013) denomina criterios informales 5 . Entiéndase por informal aquel procedimiento que no se hace de acuerdo con las formas o moldes que estipula la ley, sin que eso signifique que sea ilegal.

En la investigación llevada a cabo por Montoya (2013) se pueden resaltar dos criterios informales de la elección de los magistrados, que son criterios sociodemográficos e instituciones informales. El primero corresponde a condiciones tales como la región, el género, la ideología y la cercanía con partidos políticos. Por ejemplo, en los resultados de esta investigación se evidencio que en Colombia los hombres tienen mayor probabilidad de ser elegidos que las mujeres; respecto de las instituciones informales, el principal es el lobby; este a su vez se divide en dos, lobby directo, que es el cabildeo que realizan los candidatos con cada una de las fuerzas políticas en el senado, y el lobby indirecto, que es producto de los padrinazgos políticos que puedan tener los candidatos para ayudar a su elección.

Este tipo de criterios informales a la hora de la elección de los magistrados puede verse más marcado de acuerdo con la forma en la que estos sean elegidos. En caso de que la elección se desarrolle por medio de un concurso de méritos, es probable que se vean disminuidas las influencias que puedan tener los criterios informales y que predominen los establecidos en la ley. Por el contrario, en caso de que la elección se dé por voto popular, los criterios informales pueden llegar a tener mucha más influencia, ya que, como se mencionó anteriormente, los candidatos a estos cargos pueden aliarse con los políticos para lograr ser elegidos y poner así en riesgo la imparcialidad de sus decisiones.

\section{La naturaleza política del Tribunal Constitucional}

A lo largo de la historia se ha buscado que el poder judicial se mantenga independiente de los demás poderes. En la Edad Media, este

\footnotetext{
${ }^{5}$ Cabe aclarar que para Montoya (2013) este tipo de instituciones informales no son necesariamente perjudiciales para la democracia, pues en ocasiones viene a llenar vacíos legales (p. 166).
} 
Jaime Cubides Cárdenas - Sebastián Rangel Salazar - Laura Milena Beltrán Galvis Independencia y legitimidad de la jurisdicción constitucional: en perspectiva Colombia - Bolivia

poder pertenecía al rey; posteriormente, con las revoluciones burguesas y la Ilustración, autores como Montesquieu desarrollaron la teoría de separación de poderes en poder ejecutivo, poder legislativo y poder judicial como un rechazo a la concentración de poderes en el rey y a la idea de que Luis XIV perpetuó en la frase: “El Estado soy yo" (Fioravanti, 2001).

En la actualidad, la gran mayoría de los estados democráticos mantiene esta división de poderes; sin embargo, la discusión en torno a la politización de la justicia es cada vez más relevante (Ferejohn et ál., 2008), sin que ello signifique un choque de poderes, sino una colaboración armoniosa entre estos. Los tribunales hoy día en América Latina tienen una naturaleza política que va desde sus orígenes hasta sus funciones. El desarrollo de los tribunales constitucionales en esta región está marcado por acontecimientos histórico-políticos; cuanto más sean estos hechos los que dan origen al Tribunal Constitucional, más tendrá una naturaleza institucional política (Tarapués, 2009).

En lo referente a sus funciones, los tribunales constitucionales tienen la inherente función del control de la constitucionalidad. Lo que antes eran cuestiones políticas, abordadas por el legislativo y el ejecutivo, ahora son conflictos dirimidos por la jurisprudencia. De estos casos, uno de los más importantes en América Latina es el de Colombia, donde a partir de la Constitución de 1991 se crea la Corte Constitucional, institución que marca la diferencia entre Estado de derecho y Estado constitucional de derecho y que sirve de claro ejemplo de la judicialización de la política.

A partir de 1991, el sistema judicial colombiano comenzó a desempeñar un papel clave en la protección de los grupos minoritarios, evitar los excesos gubernamentales en estados de excepción, el manejo de la política económica y el desarrollo de la autonomía individual (Ferejohn et ál., 2008). En estos casos se destaca a la Corte Constitucional con sentencias sobre la dosis personal (C-221 de 1994) o la sentencia sobre la eutanasia (C-239 de 1997). Si bien en Colombia existe el control de constitucionalidad desde 1910, en esta época el alcance de los derechos sociales se consideraba como una tarea 
del legislador y no es hasta después de 1991 que estos asuntos son tratados por el poder judicial (Ferejohn et ál., 2008).

Como consecuencia de esta nueva forma de desarrollar sus funciones por parte de las altas cortes, podemos decir que se han fortalecido aún más las ideas de judicialización de la política y politización de la justicia, sin que ello signifique un choque de poderes, sino un avance importante en el derecho constitucional latinoamericano (Ferejohn et ál., 2008).

\section{Interrogantes al Tribunal Constitucional Plurinacional de Bolivia}

En el año 2009 entra en vigor la nueva Constitución Política Plurinacional del Estado de Bolivia, en la que se da origen al hoy conocido Tribunal Constitucional Plurinacional (en adelante TCP); en el artículo 197 del texto constitucional, inciso 3, dice: "La composición, organización y funcionamiento del Tribunal Constitucional Plurinacional serán regulados por la ley". Es por esto por lo que el 6 de julio de 2010 se promulga la ley 027, encargada de desarrollar el citado inciso. En el artículo 13 de esta ley se habla sobre la integración del tribunal constitucional, que estará conformado por siete magistrados y magistradas permanentes y siete magistrados y magistradas suplentes; de estos, al menos dos deberán provenir del sistema indígena originario campesino.

En el artículo 198 de la Constitución se establece que estos magistrados deberán ser elegidos por voto universal; por esta razón, en la ley 027 de 2010 se regula su proceso de elección. El proceso puede dividirse en dos etapas: en la primera se da la elección de los candidatos, la cual lleva a cabo la Asamblea Legislativa Plurinacional, que debe realizar una convocatoria seis meses antes de la terminación del periodo de los magistrados en el cargo (periodo individual de seis años). Con dos tercios de los miembros presentes, la Asamblea deberá escoger a 28 postulantes, de los cuales la mitad deben ser mujeres (Millán, 2015). Como segunda etapa, el órgano plurinacional electoral deberá proceder a la organización del proceso electoral en circunscripción nacional. 
Jaime Cubides Cárdenas - Sebastián Rangel Salazar - Laura Milena Beltrán Galvis Independencia y legitimidad de la jurisdicción constitucional: en perspectiva Colombia - Bolivia

Los candidatos no podrán hacer campaña para ser elegidos por sí mismos o por terceras personas. Una vez concluidas las votaciones, los siete candidatos más votados ocuparán el cargo de magistrado del TCP y los siete siguientes el de suplentes. Como se evidencia, la elección de los magistrados de las altas cortes bolivianas corresponde a la elección por voto universal, que, como se analizó anteriormente, tiene como consecuencia una politización de la justicia que no da imparcialidad a las decisiones de estos tribunales; en palabras de Duverger:

No ha dado buenos resultados [...] Primero, no ha dado ninguna garantía de competencia jurídica. Después, para afrontar las elecciones, los candidatos a las funciones jurisdiccionales han tenido que aliarse con los partidos políticos, lo que tampoco asegura garantías de imparcialidad. (Duverger, 1980, p. 228)

Un ejemplo de la debilidad de la imparcialidad del TCP es la sentencia 0087 de 2017, en la que este Tribunal, basándose en el derecho a la reelección y en el control de convencionalidad de acuerdo con el artículo 23.16 de la Convención Americana de Derechos Humanos, concedió a Evo Morales la posibilidad de reelegirse por una cuarta vez en el cargo de presidente del Estado plurinacional de Bolivia, a pesar de que tan solo un año antes, mediante un referéndum en el que se buscaba la modificación del artículo 168 de la Constitución para eliminar el límite de dos periodos para quienes ocupen el cargo de presidente y vicepresidente, el pueblo le había negado dicha posibilidad.

Debe tenerse en cuenta que desde el año 2009, las mayorías del Congreso boliviano han sido constituidas por el partido Movimiento al Socialismo, partido de Evo Morales. Esto puede tener consecuencias en la elección de los candidatos al TCP, quienes son elegidos por la Asamblea Nacional Legislativa (Nocera, 2019).

6 "b) de votar y ser elegidos en elecciones periódicas auténticas, realizadas por sufragio universal e igual y por voto secreto que garantice la libre expresión de la voluntad de los electores [...]". Convención Americana de Derechos Humanos, artículo 23, literal b. 
Esto ha puesto en riesgo la democracia en el país y acentuado aún más un régimen presidencialista característico de los países latinoamericanos (Cárdenas y Corredor, 2018). Además, pone en tela de juicio la legitimidad del TCP, ya que — si bien sus miembros son elegidos por voto universal, lo que les da mayor legitimidad - con esta sentencia fueron en contra de una decisión popular (Inarra, 2019).

Esta sentencia ha recibido varias críticas, por lo que se considera fue una interpretación inadecuada de la Convención Americana sobre Derechos Humanos. El TCP se ocupó solamente del artículo 23 de la Convención y pasó por alto el artículo 32.2, según el cual "Los derechos de cada persona están limitados por los derechos de los demás, por la seguridad de todos y por las justas exigencias del bien común, en una sociedad democrática". Este artículo habilitaría la restricción a la reelección presidencial que fue acogida por la mayoría popular en el referendo de 2016, la cual fue desconocida por el TCP en la sentencia (Inarra, 2019).

\section{Conclusiones}

A modo de conclusión, es necesario dar respuesta a la pregunta de la investigación propuesta. Si bien los tribunales constitucionales tienden a ser órganos contramayoritarios, no se puede negar que su papel es muy importante para el desarrollo del proceso democrático. Estos tribunales son órganos que tienen una naturaleza política y debido a las reformas constitucionales de los últimos años, la judicialización de la política ha crecido y se mantiene como una función importante para la protección de los derechos fundamentales y sociales, puesto que estas cortes contribuyen a su protección y son garantía de la participación de todos en el proceso democrático.

Respecto a la elección de los magistrados de los tribunales constitucionales, nos acogemos al método de elección por carrera administrativa como el medio idóneo por el cual se garantiza la imparcialidad e independencia de sus miembros. Sin embargo, sin despreciar los avances importantes que se puedan hacer para asegurar una elección transparente, estos métodos no son una 
Jaime Cubides Cárdenas - Sebastián Rangel Salazar - Laura Milena Beltrán Galvis Independencia y legitimidad de la jurisdicción constitucional: en perspectiva Colombia - Bolivia

garantía total de que la actuación de los miembros de estas corporaciones sea imparcial e independiente, porque, primero, hay que reconocer que desempeñan un papel político importante en la transformación social y, segundo, porque al final la neutralidad de sus decisiones recae en su consciencia.

Finalmente, es preciso resaltar que el avance boliviano de elegir a los magistrados del TCP por medio de elección popular brinda más legitimidad a estos y que no necesariamente, como se cree a primera vista, ello implica que el cabildeo que hagan o las fichas que muevan para ser elegidos constituye una ruptura con su independencia, aunque, como se mencionó anteriormente, sea preferible que los procesos de elección se acojan al método de carrera administrativa para maximizar las posibilidades de tener excelentes defensores del orden constitucional.

\section{Referencias}

Agudelo, C. (2014). La democracia de los jueces: La "rama menos peligrosa" como poder prodemocrático en la práctica constitucional. Editorial Leyer.

Asamblea Legislativa Plurinacional. (2010, 6 de julio). Ley 027. Gaceta Oficial de Bolivia. https: / / bit.ly / 2OyjmzF

Bickel, A. (1962). The Least Dangerous Branch: The Supreme Court at the Bar of Politics. The Bobbs-Merrill Co.

Cárdenas, E. y Corredor, F. (2018). El juez constitucional y la reelección presidencial en América Latina. Revista de Economía Institucional, 20(38), 45-70. https: / / bit.ly/30Kwmol

Constitución del Estado Plurinacional de Bolivia. (2009). Gaceta Oficinal de Estado Plurinacional de Bolivia.

Corte Interamericana de Derechos Humanos. (2006, 23 de noviembre). Niñas Yean y Bosico vs. República Dominicana. https: / / bit.ly/38zFjVK

Duverger, M. (1980). Instituciones Políticas y Derecho Constitucional. Ediciones Ariel. Ferrajoli, L. (1999). Derechos y garantías. La ley del más débil (3. ${ }^{a}$ edición; P. Ibáñez y A. Greppi, trad.). Trotta.

Ferejohn, J. Ansolabehere, K. Dallas y Uprimmy, R. (2008). Los jueces: entre el derecho y la política. Editorial Instituto Latinoamericano de Servicios Legales Alternativos.

Fernández, S. (1993). Reflexiones en torno a la Composición del Tribunal Constitucional en España. THEMIS: Revista de Derecho, (26), 15-28. https:/ / bit. ly/38Gx4Ho 
Fioravanti, M. (2001). Constitución, de la antigüedad a nuestros días. Editorial Trotta. Gargarella, R. (2019). Constitución y democracia. Algunas lecciones aprendidas y algunas lecciones que aprender. Derechos Fundamentales a Debate, 10, 8-22. https: / / bit.ly/3vqbMHO

Inarra, L. (2019). La limitación constitucional a la reelección de autoridades ejecutivas, su convencionalidad y legitimidad popular: una crítica a la sentencia del Tribunal Constitucional Plurinacional boliviano. Razón Crítica, (6), 237-55. https: / / bit.ly/3ljlPtQ

Millán, Ó. (2015). El sistema electoral para la elección de los magistrados del Tribunal Constitucional Plurinacional. Revista Ciencia y Cultura, 19(35), 10732. https:/ / bit.ly/3rMkazh

Montoya, A. M. (2013). "Si no vas al senado no te eligen magistrado". Instituciones informales y criterios de selección de los magistrados de la Corte Constitucional colombiana en el Senado (1992-2009). Colombia Internacional, 79(septiembre-diciembre), 155-90. https: / / bit.ly/3cx6npW

Nino, C. S. (1989). La filosofía del control judicial de constitucionalidad. Revista del Centro de Estudios Constitucionales, (4), 79-88. https: / bit.ly/3tjIqJn

Nocera, L. A. (2019). Contradicciones constitucionales: el Tribunal Constitucional plurinacional boliviano y la reelección de Morales: ¿una práctica de abusivismo constitucional? Anuario Iberoamericano de Justicia Constitucional, 23(2), 491-506. https: / / bit.ly/3qKAtv5

Nogueira, H. (2003). Los Tribunales Constitucionales de Sudamérica a principios del Siglo XXI. Ius et Praxis, 9(2), 59-131. https: / / bit.ly /3tctVHc

Rivera León, M. A. (2010). Jurisdicción constitucional: ecos del argumento contramayoritario. Cuestiones Constitucionales, 22(enero-junio), 223-60. https: / / bit.ly /3qLj5q9

Tribunal Constitucional Plurinacional de Bolivia. (2017, 28 de noviembre). Sentencia 0087 de 2017. (Zenón Hugo Bacarreza Morales, M.P.). https: / / bit. ly/30GKBKC

Tarapués, D. (2008). La naturaleza institucional del Tribunal Constitucional en América del Sur. Editorial Universidad Santiago de Cali.

Vanegas, H. (2015). Legitimidad de los Tribunales Constitucionales en el ejercicio del control de constitucionalidad, estudio de jurisprudencia en Colombia [tesis de pregrado, Universidad Católica de Colombia]. Repositorio Universidad Católica de Colombia. https: / / bit.ly/3ticKnF

Vázquez, R. (2010). Justicia constitucional, derechos humanos y argumento contramayoritario. Anales de la Cátedra Francisco Suárez, 44, 249-264. https: / / bit.ly/3bNoTeg

Verly, H. (1991). El Argumento Contramayoritario: Justificación del control judicial de constitucionalidad. El Derecho. 